\title{
Underground mineral processing - Gekko Systems modular Python
}

\author{
J Baines Gekko Systems Pty Ltd, Australia \\ T Bell Gekko Systems Pty Ltd, Australia \\ N Grigg Gekko Systems Pty Ltd, Australia
}

\begin{abstract}
Underground mining technology advancements and automation have progressed significantly in the past 50 years; often the refinement of existing equipment, and the automation thereof, which in effect does the same thing. It's often about progressing mining methods that have incremental impacts, rather than step-change benefits. Processing, both currently and traditionally, has been a function that takes place on the surface in the vast majority of cases, with preludes into processing underground remaining at crushing only.
\end{abstract}

This paper examines the benefits of underground processing as a viable, game changing and sustainable option in the right application of amenability with the orebody and operating environment. It will provide an overview on pre-concentration utilising gravity separation and flotation; both proven physical processes that minimise the need for toxic chemical processes.

As well as the inherent benefits of minimising surface disturbance with underground processing, the possibilities of using underground plant residue placement as backfill removes one of the biggest operating cost impacts; residue/tailings placement and storage facility construction. There will be a summary of the commercial benefits around haulage reduction, and operational benefits analysis looking at the impacts of 'mine call factor' and what better management of this can do to the overall economics of an underground mine. Of all the measurable economic benefits of underground pre-concentration (processing), the single biggest benefit is measured in lowest life-of-mine costs through reduction of cut-off grade; this provides increased reserves with no additional input of capital. Analysis of a summation of benefits concluded that the overall operating cost of a suitable mining operation could possibly be reduced by up to 50\%, and this paper will highlight why, and how, this can be a reality.

In conjunction to the environmental and commercial benefits, there will be a presentation of the engineering aspects associated with such an underground plant, its design requirements, strength testing processes, dimensions and suitability to common drive/tunnel sizes. This paper will address the practical aspects of what it takes to make this concept a commercial and operational reality; addressing areas associated with module turning circles, transport, towability (mobility) and levelling using hydraulic jacks. There will be presentation of bogey wheel design and critical design elements for operator safety.

Automation is a key component; there will be information that highlights why this approach has the potential to round out modern thinking with respect to remote mining equipment. The goal for underground processing is to run the plant completely remotely with minimal maintenance requirements, reducing exposure to the underground environment and, in the process, making mining safer whilst utilising state-of-the art automation practice.

Challenges associated with underground processing, both technical and human, will be summarised. It will demonstrate that with a shift in thinking and collaborative courage between all the required disciplines, step-change benefits can be made for the betterment of a more efficient and sustainable industry.

Keywords: underground processing, Python, mine equipment and automation, mine economics 


\section{Introduction}

Mining methods have evolved over a number of years, however, generally speaking, many of the improvements in underground mining methods have come about by increasing the efficiencies of older methods.

The concept of underground processing has been around for a while, with the first reported underground gravity gold processing plant operated between 1991 and 1999 by Welsh Gold PLC at their Gwynfynydd gold mine in north Wales, United Kingdom. In 1996, Sedimentary Holdings Pty Ltd applied to patent the concept of continuous mining by road header, crushing and sizing, conversion to a slurry and then concentration using InLine Pressure Jigs (IPJs) (Devereux \& Gray 1996). At that time, the road header technology limited the invention's applications.

In the intervening years, processing technology, automation and engineering have advanced to the point where underground processing is now more practical than ever, and the benefits of underground processing can be more easily realised.

Gekko Systems (Gekko) has taken advantage of these advancements to design the 'Python', which has potential as a modular, standard application of fine crushing and gravity rejection that may be directly applicable to many gold operations.

The Python, shown in Figure 1, has been designed to exploit mineralogical properties that are common in gold ores with a simple flow sheet that utilises common and effective crushing, screening and concentration equipment on a scale that can be installed and operated underground in a $5 \times 5 \mathrm{~m}$ drive.

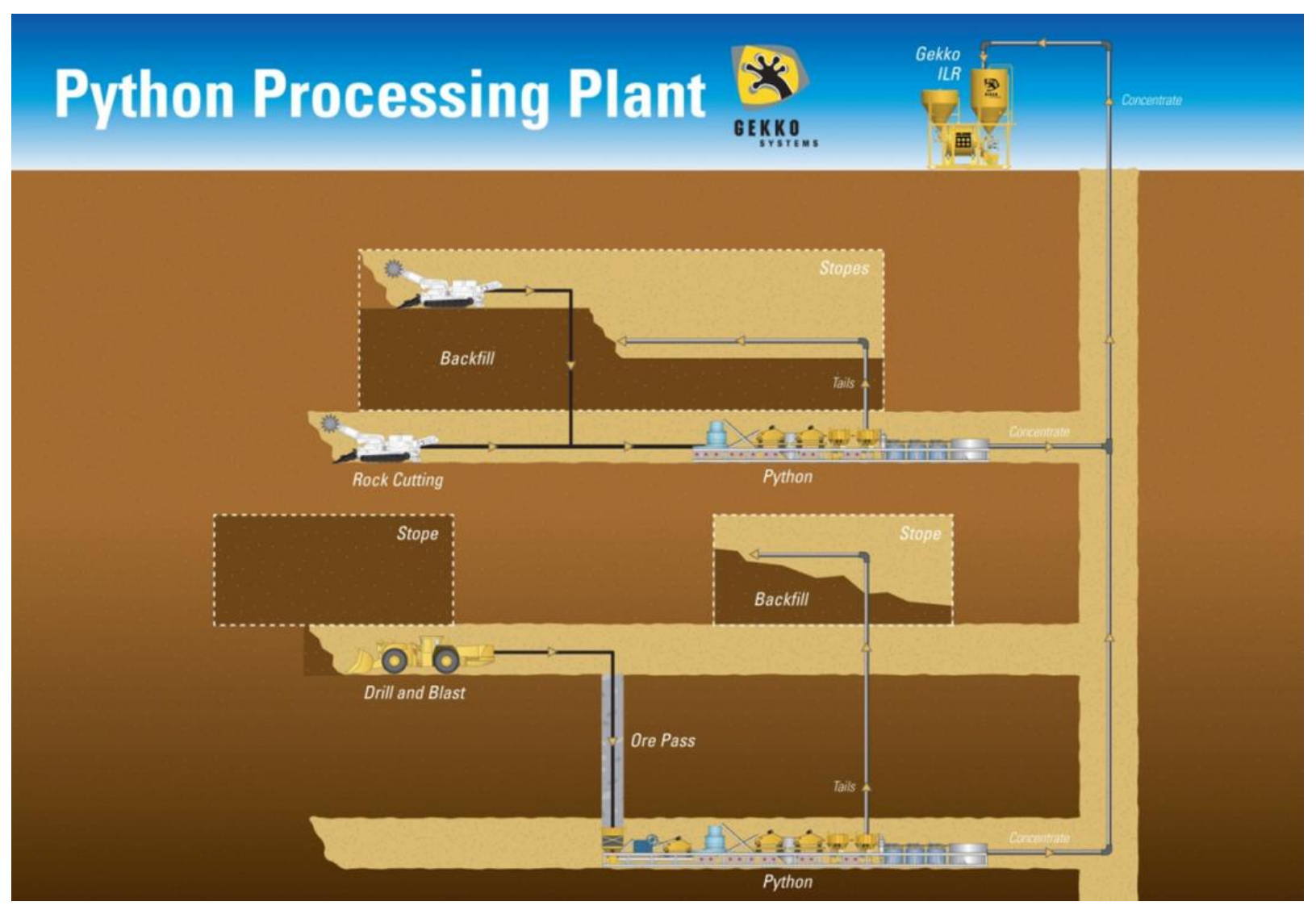

Figure 1 Python- underground conceptual design

The components of the Python are designed and constructed as modules on movable skids so that, within reason, a range of crushing, screening or concentrating components can be added or removed as required. This enables flexibility in design of a Python flow sheet, so that individual project needs can be met without the requirement to completely re-design and engineer the components. 
The concept of pre-concentration appeals to processing engineers because it concentrates the valuable minerals in a relatively small stream for more traditional above-ground processing. The application of the pre-concentration concept, underground or as near as practical to the mining operation, has the potential to lead to additional operational, health and safety, as well as environmental benefits.

In a recent review, Lane et al. (2008) noted that underground pre-concentration is likely to result in significant savings in ore hoisting and trucking costs if $40 \%$ of the ore (or concentrate thereof) could be taken to surface. Bamber et al. (2005) suggest a number of advantages for underground processing, including; reduced haulage and transport costs, lower cutoff grades due to reduced costs, increased reserve base due to lower cutoff, reduced mining selectivity needs, bulk mining approaches, and improved ground conditions due to availability of coarse backfill from the plant.

Typical grades against contained gold are given in Figure 2 (Grigg \& Delemontex 2015), demonstrating the significant difference that a change in cutoff grade can make.

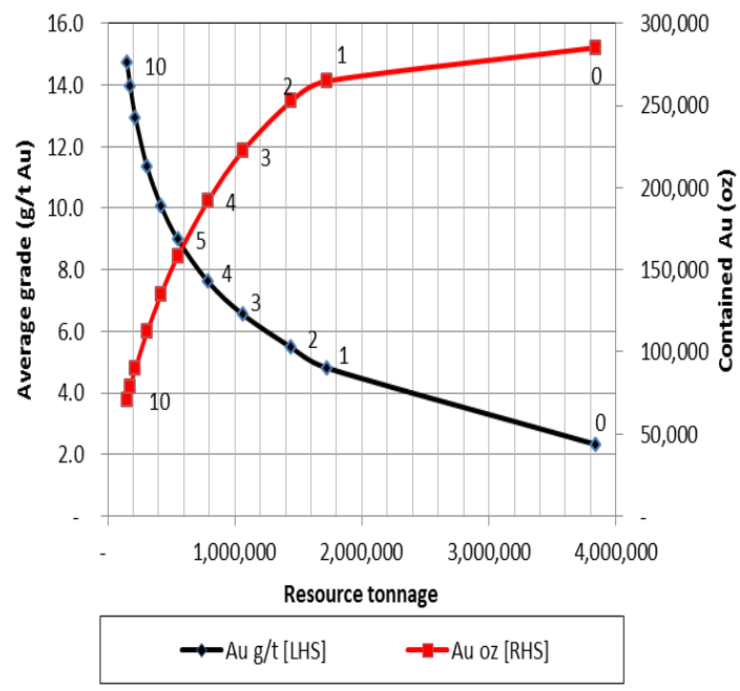

Figure 2 Typical grade-tonnage graph

Bamber et al. (2006) describe previous work undertaken to evaluate the potential of underground pre-concentration, predominantly in South African gold mines, with some of the cost impacts quantified in Figure 3. They concluded that "the implementation of pre-concentration underground will result in substantial capital and operating cost savings, thus lowering the cut-off grade and increasing the potential reserve, as well as increasing the value of ore delivered to the surface" (Bamber et al. 2006).

\section{Greenfields capital cost impacts}

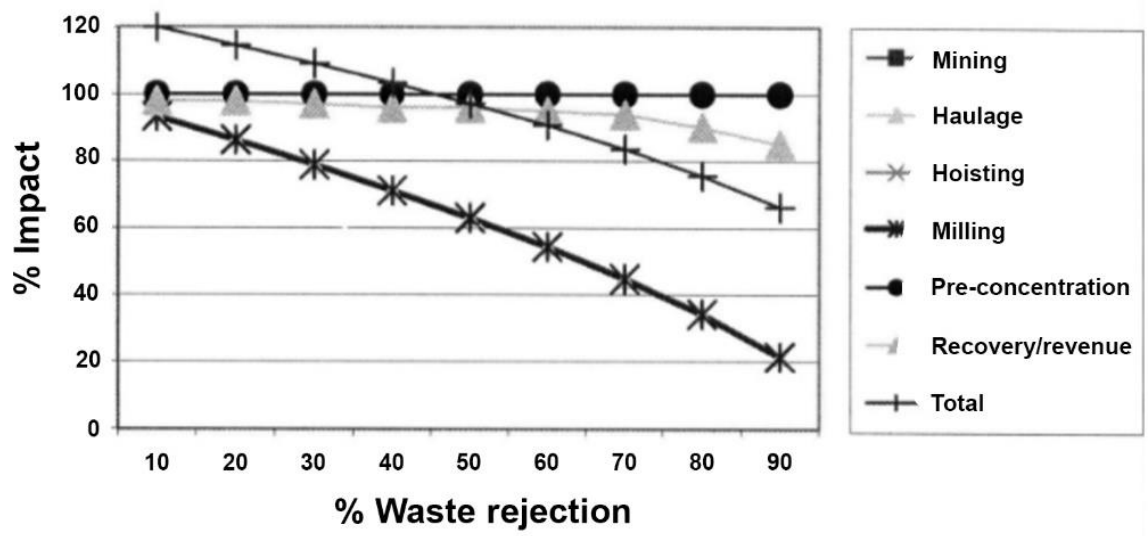

Figure 3 Effect of waste rejection on greenfields capital costs (Bamber et al. 2004) 
Significantly reduced power costs were obtained in modelling calculations performed for Castlemaine Goldfields's (CGT) fine crushing circuit, compared to a SAG (semi-autogenous grinding) milling circuit (Grigg \& Delemontex 2015). A reduction from 16.15 to $4.45 \mathrm{kWh} / \mathrm{t}$ was modelled, with full data given in Table 1.

Table 1 Fine crushing power requirements - three stage crushing versus SAG design

\begin{tabular}{lllll}
\multicolumn{2}{l}{ CGT crusher operating power } & & & SAG design \\
& Feed & Product & Energy & Energy \\
\hline Jaw & $\mathrm{P}_{80} \mathrm{~mm}$ & $\mathrm{P}_{80} \mathrm{~mm}$ & $\mathrm{kWh} / \mathrm{t}$ & $\mathrm{kWh} / \mathrm{t}$ \\
Cone & 450 & 150 & 0.15 & 0.15 \\
VSI* & 150 & 40 & 0.37 & \\
Final crush & 40 & 0.9 & 3.93 & 16 \\
& & & 4.45 & 16.15 \\
\hline
\end{tabular}

*Vertical shaft impactor.

Pre-concentration results in an increase in gold grade which increases the value of product delivered to the surface, however, it delivers equal value as a waste rejection circuit. By isolating a waste stream early in the mining/processing operation, the project can benefit from:

- Not incurring the cost of transporting the waste mass to the surface.

- Not exposing the waste rock to more processing and cost than is absolutely necessary.

- Immediately making the waste rock available for mining backfill.

- Not storing the waste in traditional above-ground tailings storage facilities.

By not incurring the cost of moving and over-processing material that does not warrant it, the cost per tonne of ore is effectively decreased, hence the opportunity exists to make lower grade ore profitable, thereby increasing the minable reserve and life-of-mine.

The reduction in ore hauled to the surface can result in the following efficiencies for the downstream operations for a comparable production rate:

- Smaller haulage system capacity requirements.

- Fewer handling points en-route to the above-ground processing facility (less opportunity for gold loss), which will result in improved mine call factor.

- Reduced capital expenditure and operating expenditure for above-ground facilities as decreased tonnages will need to be processed for the same gold production rate.

- Less surface disruption and environmental disturbance.

- Reduced project energy and water requirements.

For underground processing to be practically achievable, it must also overcome the physical limitations of manoeuvring the equipment into position, setting up, and reliably operating in a relatively confined space. This places obvious constraints on the capacity of the underground processing facility. At present, no formal or study work has been done on the impact of a Python unit on ventilation; however, proof of concept operation on surface in South Africa has yielded no proportional increase significant enough to impact existing ventilation systems. 


\section{Python flow sheet and proven metallurgy}

One of the most significant cost and environmental issues in processing is comminution. As the target $\mathrm{P}_{80}$ grind becomes finer, the energy and associated costs rise exponentially. If a critical mineral can be liberated and recovered at a coarse particle size, it is a major environmental, throughput and cost advantage.

In a typical gold processing flow sheet, crushing is generally undertaken first to bring the particle size down to around 8 to $12 \mathrm{~mm}$. Further comminution by grinding mills reduces the size down to the required level of $\mathrm{P}_{80}$ to between 75 to $106 \mu \mathrm{m}$ for carbon-in-leach (CIL) circuits.

Critical to the concept of the Python is the initial targeting of a coarser particle size distribution to liberate the gold-bearing minerals and maximise their recovery to a gravity and flotation concentrate. Any further fine grinding to liberate the discrete gold particles for maximum leach extraction is then only required on the pre-concentrated Python product in the above-ground facility.

The effect of grind size on gravity gold recovery for ore from the Ballarat Goldfields is demonstrated in Figure 4. This data demonstrates how gravity recovery of gold can be improved at coarser particle size distributions on amenable orebodies. Overgrinding the sulphide particles, which often contain the gold, can be detrimental to both gravity and flotation recovery.

\section{Combined Tabling Recovery Yield Curve}

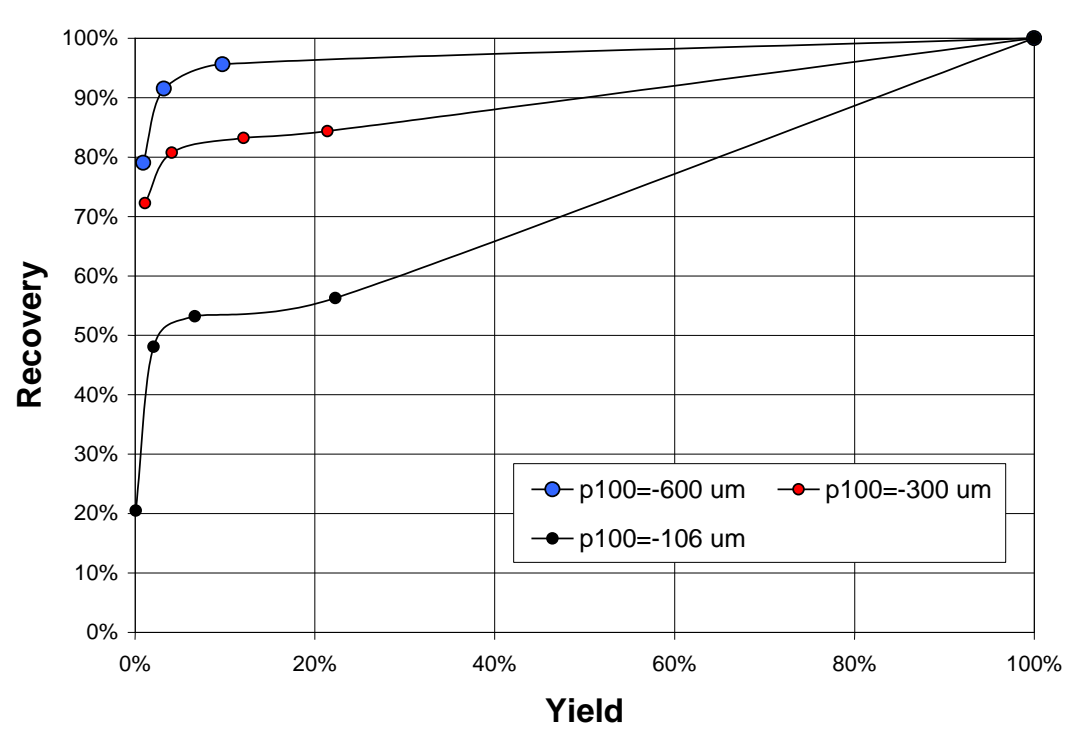

Figure 4 Effect of overgrinding on gravity gold recovery by yield (mass pull \%)

Fine crushing devices such as a VSI, high pressure grinding rolls (HPGR) and hammer mill (HM) can be used to liberate gold without the effect of flattening and smearing. In essence, low aspect ratio-shaped particles are typical in a crushing circuit, whereas grinding mills tend to flatten free gold and overgrind sulphide minerals. The premise of gravity separation is the coarser the mineral liberation (particle size), the higher the probability of effective recovery (Grigg \& Delemontex 2015).

Flash flotation is commonly used to float sulphide minerals from the coarse recirculating load of a milling circuit and is an obvious supplement to gravity concentration as it has the potential to recover finer minerals that would otherwise be missed by a gravity-only circuit, as shown in Figure 5 . The complimentary nature of combining flotation with gravity for the pre-concentration of gold is ideal for an underground processing option. 


\section{Combined size by size unit gold recoveries of IPJ and flash flotation}



Figure 5 Combined IPJ and flash flotation recovery by size

Gekko Systems's database indicated that testing on over one hundred ore samples from across the world has shown a high potential for recovery based on gravity supplemented with flotation, as shown in Figure 6.

Gravity Only vs Gravity + Flotation Recovery All Gekko Data

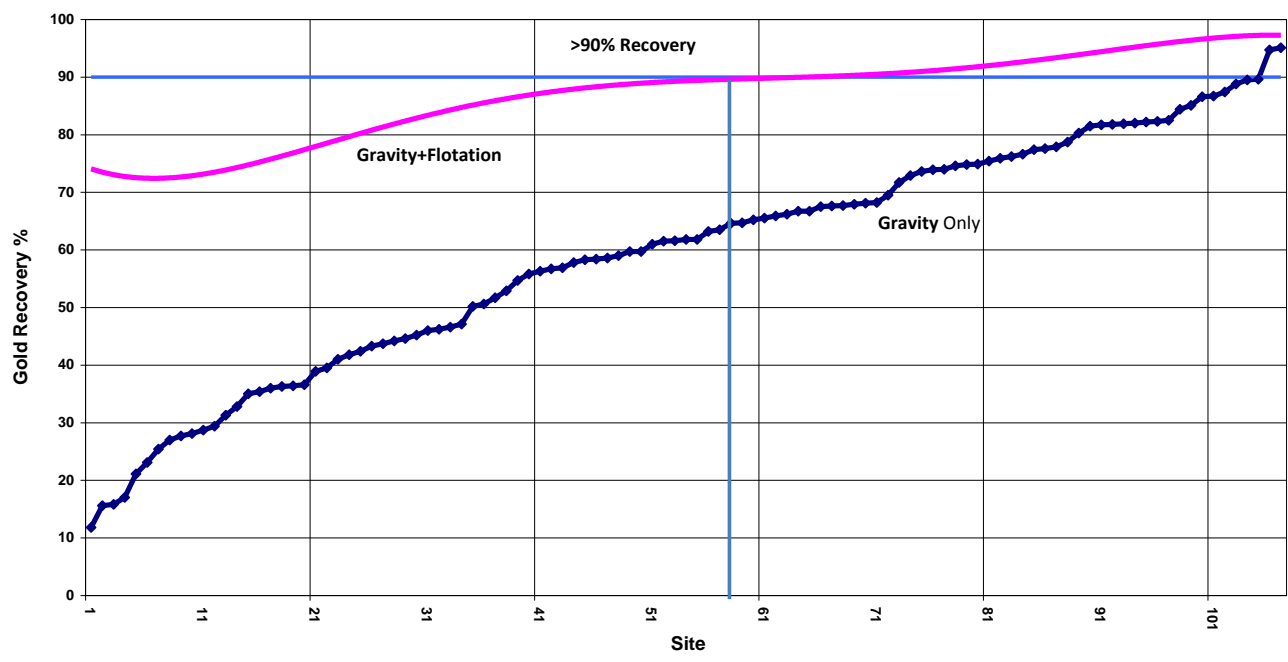

Figure 6 Continuous gravity recoverable gold (CGR) and CGR supplemented by flotation data

Although each ore must be tested for amenability, the Python flow sheet is designed to exploit these mineralogical properties that appear to be common across many gold orebodies with a simple flow sheet that employs fine crushing, gravity concentration and/or flotation.

The conceptual Python flow sheet is shown in Figure 7, and it demonstrates how the concepts of fine crushing can be combined with gravity and flotation to pre-concentrate gold and isolates barren tailings that does not warrant any additional processing and cost. 


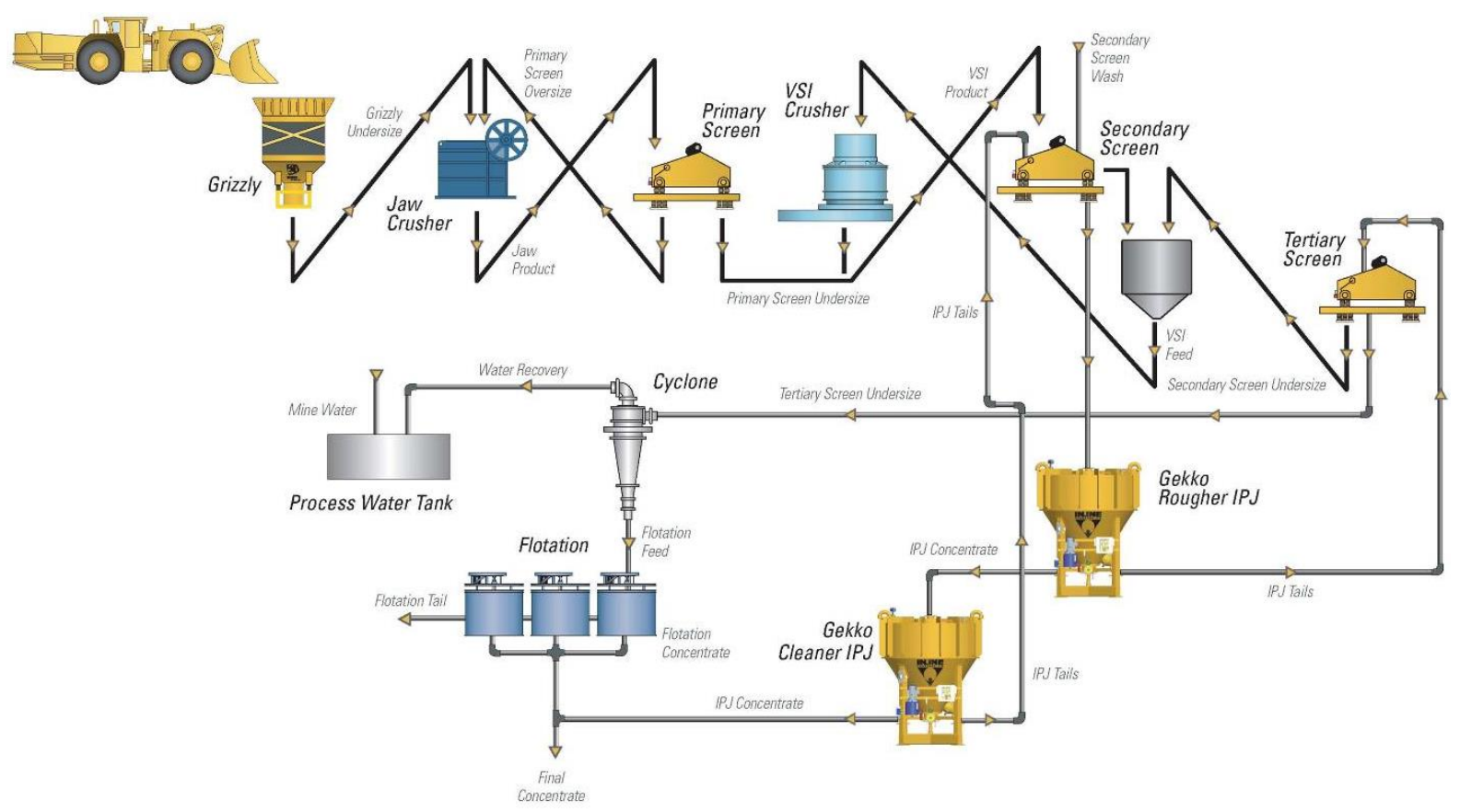

Figure 7 Python flow sheet - fine crushing, gravity and flotation

Conceptually, the Python is designed to pre-concentrate the gold into 10 to $40 \%$ of the original mass. In an underground pre-concentration application, a concentrate mass recovery of 35 to $40 \%$ would be targeted, and the tailings generated would be used as mining backfill. Depending on the swell factor (volume change after crushing and processing), this volume may need to be changed to suit individual orebodies.

The application of sulphide flotation also has the benefit of reducing the sulphide content in the tailings, which will make it more attractive to be used as backfill material with reduced potential for acid mine drainage.

\section{Python underground modules}

The Python system consists of five key connecting components:

1. Coarse and fine crushing.

2. Screening.

3. Gravity and/or flotation separation.

4. Concentrate handling.

5. Tailings disposal systems.

Each section is designed as a skid-mounted, transportable module that can be transported down a $5 \times 5 \mathrm{~m}$ drive. To move the Python modules into place, a system of two bogies that fit under either end of the individual modules is used. The bogies are designed to carry a maximum 24 tonnes and have a rollover Factor of Safety of 0.76 with a theoretical cornering speed of $26 \mathrm{~km} / \mathrm{h}$. However it is recommended the unit is towed at no greater than $10 \mathrm{~km} / \mathrm{h}$. New designs can be developed to suit individual applications.

Transport height is restricted to $3.5 \mathrm{~m}$ so that the total height is no more than $4 \mathrm{~m}$, including bogies during the transportation stage. This restriction ensures that the modules don't impact on mine services running down the decline. This is achieved with minimal equipment removal and the use of hinged boxes to make replacement of equipment easier. An example of a Python module is shown in Figure 8.

The turning circle of a 50 tonne (capacity) underground truck was used in the design of the required turning circle of a Python module as this was thought to be a worst case scenario. 
These factors restrict the length of any single module to $7.7 \mathrm{~m}$ and results in the need to use two load-haul-dump units to push/pull the modules down the mine to get them around tight corners.



Figure 8 Skid-mounted gravity module

The modules are also designed to be installed on a sloping floor up to 1:50 slope (shown in Figure 9) as it was recognised that no drive in an underground environment can be level, due to flooding/drainage issues. The modules need to be levelled across their width (up to $2.3 \mathrm{~m}$ ) and length (up to $11 \mathrm{~m}$ ) but only very few need to be level in respect to each other.

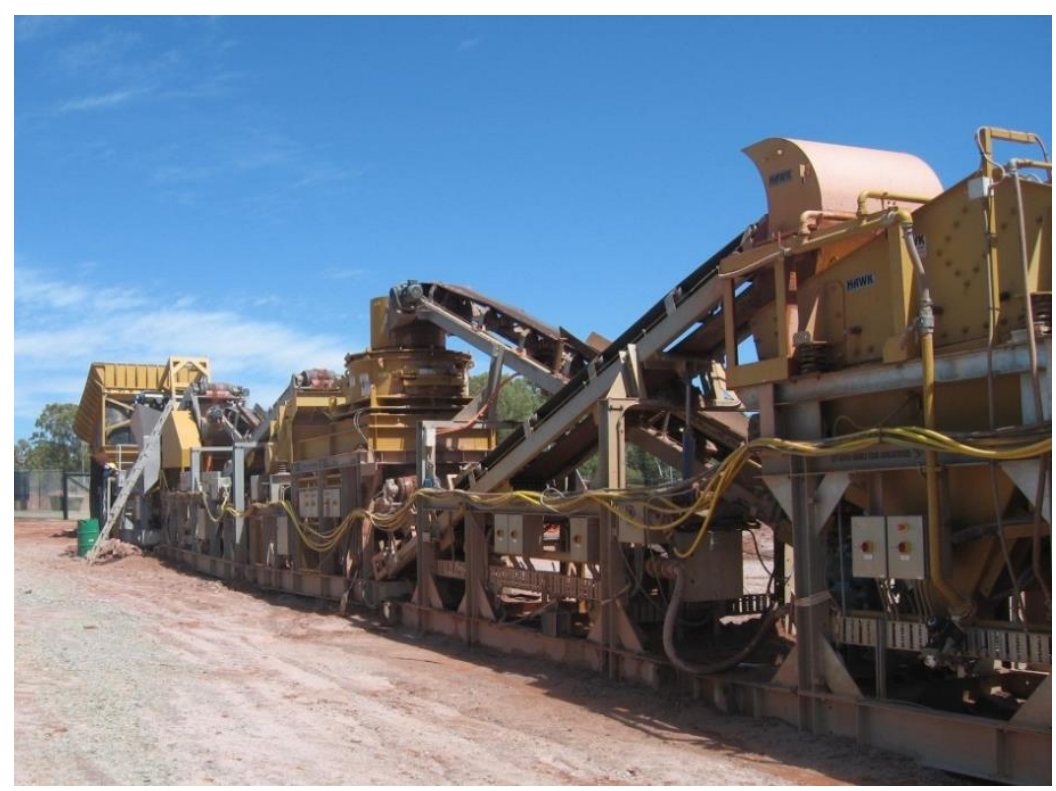

Figure 9 Python 200 installed and operating on a 1:50 slope

The modules do not need to be installed in a straight line as once the process reaches the gravity stage, all transfers are by pump and pipes and therefore the 'wet end' of the Python can be installed on a different level in the mine or, if on surface, parallel to the dry end. 
These features effectively make the Python 'plug and play', as each module is put in place, levelled, and connected to the up/downstream module. Minimal in situ engineering and construction is required to ready the plant for commissioning.

\section{$4 \quad$ Automation and control}

The Python uses a control system typical of Gekko's other modular processing systems.

The plant control mechanism is built from Allen-Bradley architecture (Rockwell Automation, Inc. 2017) to suit the hardware chosen for motor control and instrumentation. The motor currents are regulated using PowerFlex ${ }^{\circledR}$ drives and $\mathrm{SMC}^{\mathrm{TM}}$ Flex soft starters, and instrumentation is picked up via remote input/output $(\mathrm{I} / \mathrm{O})$ field nodes. The information is gathered by the ControlLogix® programmable logic controller (PLC) and shared between controllers over an Ethernet network. The system is interfaced using RSView Supervisory Edition (Automation.com 2017) for the purpose of supervisory control and data access (SCADA) process monitoring and control.

The PLC program encompasses the following tasks as a minimum:

- Automatic/manual functionality for all devices.

- Sequence stop/start/crash of the modularised plant.

- Full open and closed-loop control of appropriate analogue devices.

- Scaling and associated manipulation of analogue data.

- Interlocking.

- Fault detection and action (process faults and instrument faults).

- DeviceNet protocol data mapping.

- Ethernet messaging.

The SCADA system is built in sectioned components to represent the modular plant. The SCADA system mimics each area of the plant for the purpose of monitoring and controlling the operation of each piece of equipment. The operator can control all facets of the plant from the control room as it is possible for the plant to be monitored and controlled remotely. An example of the human-media interface (HMI) is shown in Figure 10.

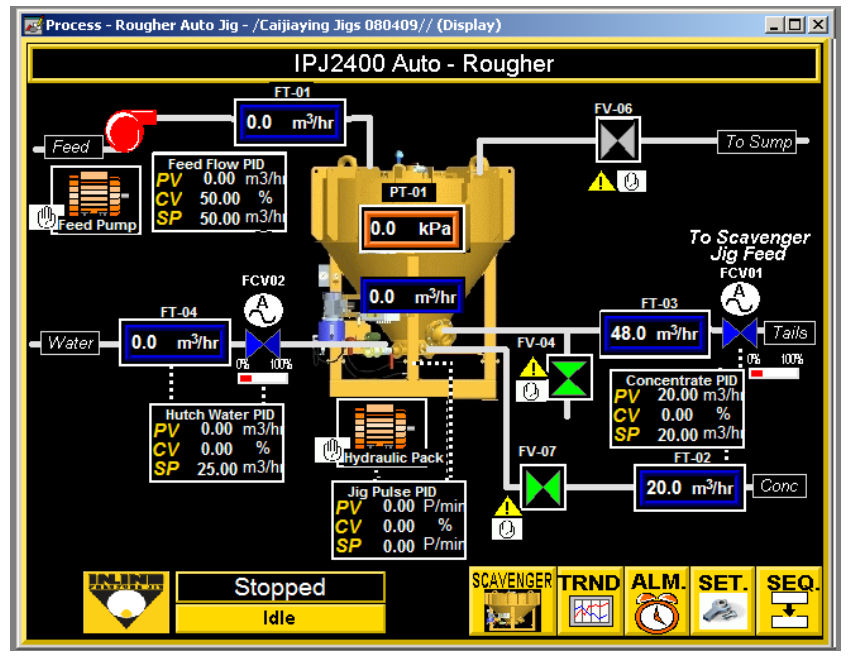

Figure 10 Automation systems - gravity jig HMI page 
The use of multiple Pythons within a distributed system allows each to be optimised for processing different sections of the orebody. The automation system monitored in real time allows the operators to change conditions at any time.

\section{$5 \quad$ Python - challenges}

Since the Python underground processing concept was conceived by Gekko in 2008, there has been a reluctance to seriously consider and run the appropriate due diligence required to implement a Python into an underground operation. The closest industry came to putting the Python underground was in South Africa, where two separate surface trials were run on prototype testing, both on a 20 tph unit (Figure 11) and a 50 tph unit (Figure 12).



Figure 11 Python 200 - first trials on surface in South Africa



Figure 12 Python 500 installed and operating on a 1:50 slope

Some of the challenges that have been expressed in recent feasibility studies include water management, metallurgists' and engineers' lack of familiarity with underground operations, underground maintenance issues, underground development costs, and harsh operating conditions.

Each of the issues needs to be addressed for individual mines and operations. The use of a 'distributed systems' model (i.e. the use of multiple Pythons underground), allows a single train to be off for maintenance, while maintaining availability of the other units and minimising the impact on production.

Given the reluctance at this stage to change conventional thinking around underground 'mining' and surface 'processing', Gekko decided to not only improve Python design, but give it the ability to be effectively utilised on-surface. Recent applications of the Python have seen it adding significant value to remote locations where containerised, pre-fabricated plant is required from a logistical perspective, such as the now operational Hope Bay operation shown in Figure 13. What has remained though is the basis of the conceptual Python thinking 
with the surface Python being low-height, skid-based, modular and there has been a direct focus maintained around maximising opportunities for energy reduction in design. There is confidence and optimism that proof of these concepts will ultimately materialise in an operating underground Python.

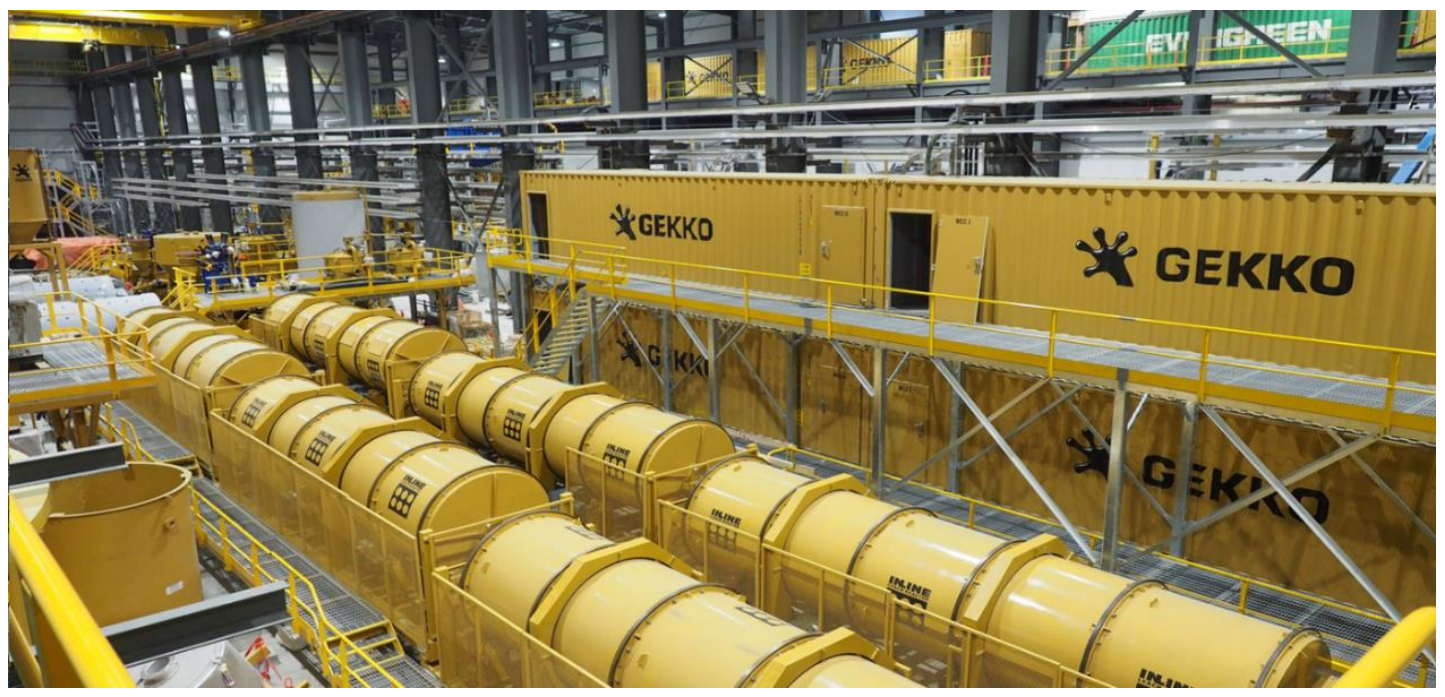

Figure 13 Hope Bay - modular Python plant and concentrate treatment plant (CTP)

\section{Conclusion}

Underground processing has the potential to make 'step-change benefits' to the mining industry. With the right orebody and amenable test work, the use of multiple underground processing plants has the potential to significantly lower capital and operational costs, but also to allow mining companies to take advantage of the many environmental and 'license to operate' benefits that underground processing has to offer. The Python underground processing technology has the potential to optimise many underground mining operations and provide a sustainable future for many mining companies.

\section{Acknowledgement}

The authors acknowledge the employees at Gekko Systems who all assisted in putting together the drawings and technical information required. The authors also acknowledge the support of Alexander Lewis Gray, technical director at Gekko Systems.

\section{References}

Automation.com 2017, RSView Supervisory Edition, viewed 22 June 2017, https://www.automation.com/automationnews/industry/rockwell-software-rsview-supervisory-edition-210-hmi-offers-new-tools-for-regulatory-compliance-support

Bamber, AS, Klein, B, Morin, M \& Scoble, MJ 2004, 'Reducing selectivity in narrow-vein mining through the integration of underground pre-concentration', InfoMine Inc., viewed 19 April 2017, www.infomine.com/publications/docs/ Bamber2004.pdf

Bamber, AS, Klein, B, Morin, M \& Scoble, MJ 2005, 'Integration of pre-concentration underground: Reducing mining costs', Proceedings of the XVII International Conference on Mine Planning and Equipment Selection, Banff, Alberta.

Bamber, AS, Klein, B, Scoble, MJ \& Widdifield, J 2006, 'Integrated underground mining and processing of massive sulphide ores,' Proceedings of the 38th Annual Meeting of the Canadian Mineral Processors, Canadian Institute of Mining, Metallurgy and Petroleum, Westmount.

Devereux, RB \& Gray, AH 1996, The Continuous Mining, Transport and Treatment System, Patent Application PCT/AU1996/000174, World Intellectual Property Organization, viewed 12 June 2017, https://patentscope.wipo.int/search/en/ detail.jsf?docld=W01996030629

Grigg, NJ \& GJ Delemontex 2015, 'The pre-concentration of precious and base metal deposits using the Inline Pressure Jig (IPJ); higher feed grades and more metal,' Proceedings of the XXVIII International Mineral Processing Conference, Canadian Institute of Mining, Metallurgy and Petroleum, Westmount.

Lane, G, Fountain, C \& La Brooy, S 2008, 'Developments in processing to match future mining opportunities', Proceedings of the First International Future Mining Conference, The Australasian Institute of Mining and Metallurgy, Melbourne, pp. 221-227.

Rockwell Automation, Inc. 2017, Allen-Bradley, viewed 22 June 2017, http://ab.rockwellautomation.com 
